\title{
Sustained Neglect in Mental Health during Nepal's Crises
}

Shiva Raj Mishra ${ }^{1^{*}}$, Pratik Khanal ${ }^{2,3}$, Vishnu Khanal ${ }^{1}$

${ }^{1}$ Nepal Development Society, Bharatpur-10, Chitwan, Nepal

${ }^{2}$ Global Health Unit, Institute of Medicine, Kathmandu, Nepal

${ }^{3}$ Karma Health, Kathmandu, Nepal

\section{Received:}

15 September 2017

Revised:

12 February 2018

\section{Accepted:}

25 February 2018

\section{${ }^{*}$ Corresponding author} shivarajmishra@gmail. com

Nepal Development Society, Bharatpur-10, Chitwan, Nepal

\begin{abstract}
Conflict in Nepal seems never resolving and the current generation has grown up in the environment of armed and political conflict characterized by indiscriminate killing, violent demonstration and widespread hostility. Adding to agony, the April 2015 earthquake left two million homeless and the 2015 Indo-Nepal economic blockade has created hostility among different community ethnic groups. With such background, this commentary highlights issues related to conflict, disaster and their relation to mental health. We also identify some gaps in existing health system, medical education and current focus on preventive approach to mental health. Mental health policy was endorsed in 1996; however, the policy has never been implemented in the fullest sense. Psychiatric services are provided by tertiary hospitals with no linkage to community-level primary health care services. Medical training still lacks mental health training at basic cadres of health workers and only small number of seats is allocated for post-graduate degree. Nepal continue to experience conflicts and disasters possibly leading to an increased burden of mental health problems and its health system is further distressed by the increasing gaps in provision of mental health service. With the devastating effect of the April 2015 earthquake, there is even higher need of serious effort to treat and prevent mental health problems with evidence-though limited depicting increase in burden of mental health problems. The state should stop putting half-hearted response to mental health problems and put more effort on long-term sustainable and culturally suitable solutions.
\end{abstract}

Keywords: conflict, mental health, Nepal

Tweetable Abstract: Despite higher burden, mental illness remains under prioritized and underfunded for prevention, care and treatment.

\section{Background}

The conflict in Nepal seems never resolving. Though the armed conflict ended in 2006, several political agitations were started by confronting political parties - in many instances leading to violent killings. The situation got tougher with the April and May 2015 earthquakes that left the country with more than 9,000 killed, 23,000 injured and more than two million homeless [1]. Agonisingly, immediately after earthquake, Nepal faced severe economic blockade from India for more than three months and an ongoing agitation in the plain area (Terai) area with widespread violence from both state and demonstrators [2].

World Health Organization (WHO) estimates that 5-10\% of the population suffer from mental health condition after humanitarian emergencies like earthquake [3]. Exposure to natural disasters leads to a wide range of mental health concerns like depression, anxiety and most importantly Post traumatic Stress Disorder (PTSD). For example, 25\% of the Haiti earthquake survivors (2010) experienced PTSD even after 2-4 months post-disaster [4].

Nepal already carried a 14\% prevalence of PTSD and a higher rate of depression and generalized anxiety prior to the earthquake owing to the consequences of armed conflict during 1996-2006 which resulted in the displacement of 200,000 and deaths of more than 13,000 population [5]. A cohort study reported a remarkable increase in the prevalence of mental illness between the early period (2000) and a later period (2007) of conflict: depression (30.0\% to $40.6 \%$ ), and anxiety (26.2\% to $47.7 \%)$ [5]. Suicide, often associated with mental health problems, is as high as 8.6 per 100,000 population in Nepal [6]. The country, in addition, does not have a national prevalence study on mental health problems which further adds to the knowledge gap in the area of mental health [7]. We express our concern on the mental health issues of survivors of Nepal's earthquakes and current ongoing crises. In this paper, we discuss about the historical burden of mental illness during Nepal's crises and neglected and half-hearted response to mental health, in particular after most unfortunate 2015 April earthquake and the 2015 economic blockade.

\section{Inequity in mental health services}

It has been more than two decades of the formulation of mental health policy [8]. However, implementation has never been materialised

This is an open access article distributed on the terms of Creative Commons Attribution3.0 license. This work may be freely reproduced, distributed, transmitted,

modified, or otherwise used provided that the original work is properly cited. Author emails are available at the end of the article. 
in its real sense. This policy envisions access to basic mental health services, training human resources, protecting human rights of the mentally ill and improving awareness about this public health issue. However, Nepal still has one of the lowest numbers of psychiatrist per 10,000 populations in the world. According to a report published in 2006 [9], there were only 32 psychiatrists $(0.129$ per 100,000 population), 6 psychologists ( 0.024 per 100,000 population), 16 unspecialized physicians in psychiatry (0.0645 per 100,000 population) and 68 nurses ( 0.274 per 100,000 population). A research done in 2011 using a standard situation analysis tool has shown a bit improvement in human resource for mental health with 0.22 psychiatrists and 0.06 psychologists for 100,000 populations-still a low figure of human resource considering the burden of the problem [10]. More to this agony of human resource gap, majority of the psychiatrists are concentrated in urban hospitals making rural areas deprived of even the basic psychiatric services. The same report further regarding the rural-urban gap in mental health services states that the density of psychiatrists in or around the largest city Kathmandu is 8.52 times greater than the density of psychiatrists in the entire country, while the figure for nurses is 6.56 [9]. This clearly shows inequity in mental health services in Nepal.

There is only one tertiary level psychiatric hospital in whole nation, and other referral hospitals which provide psychiatric outpatient and inpatient services are again as previously mentioned urban centered, and are understaffed. Issues such as long waiting hours in hospitals and high out of pocket payment for psychiatric care and medicines hinder service utilization.

A previous study by Luitel et al (2015) described the challenges for catering mental health services as well as strategies to overcome them in Nepalese health system [10]. The access to essential medicine for psychiatric illness is one of the most neglected issues in Nepal. The free health care program from government covers only 70 drugs, with inadequate psychotropic medicines [10]. Due to lack of a risk pooling mechanism such as insurance system, the poor section of population suffers disproportionately higher burden of out of pocket expenditure [11]. Catastrophic expenses in medicines are one of the several reasons driving people into poverty, which in case of mental illness often requiring a long medication, is enough for diverting chunk of family income for the treatment. This money could have been saved otherwise for education and nutrition had been there functional insurance. However, insurance system in Nepal is in juvenile stage and a majority of cost is paid as out of pocket expenses of patients and families [11]. Therefore, building a sound and universally covered insurance mechanism should be a priority for the Nepalese health system. Such mechanism should be built on the principle of risk pooling, where poor will be protected from cross-subsidy, ensuring the availability of essential mental health services and medicines irrespective of their ability to pay. Also, size of benefit package should be large enough and cost sharing should be adequate, with no financial barriers for insurance coverage for poor.

\section{Inadequate medical training}

The medical training in Nepal has often neglected training of psychiatric doctors and nurses, psychologists and other cadres of health workers. There are not enough opportunities for psychiatric training in universities. As for example, Maharajgunj Medical Campus under Institute of Medicine, the oldest medical college in Nepal, enrolled only four psychiatric doctors, three psychiatric nurses and two clinical psychologists in 2017 [12]. What would have been expected seeing the higher burden of mental health burden, is a much higher government investment in training health cadres on psychiatric care. The outlook of psychiatric profession in Nepal is gloomed by lack of recognition. The WHO report states that only two percent of the training quotas for medical doctors are devoted to mental health, and the same is provided for nurses. The existing psychiatric services treats patients with a narrow focus on alleviating the cause, however; the cause of such illnesses are multifactorial and consequences of illness would be undealt unless a comprehensive approach is sought (10). In addition to out of pocket payment, loss of productivity and discomfort has great impact to the mental, social and spiritual wellbeing of the patients and family [9]. Driving Nepal economically further on the path towards lower middle income status by 2020 requires investment in mental health as depression and anxiety cuts significant labour productivity.

\section{Mental health service gap at grassroots}

Nepal has been in decades a cradle for community-based interventions mainly maternal and neonatal health. However, similar efforts to avail necessary psychiatric services to people in need are absent. Neither there is a strong community-based effort at grassroots, nor there is a separate governing body under the Ministry of Health $(\mathrm{MoH})$ to look after mental health services provision in the country of 28 million where nearly $30-40 \%$, according to recent estimates has either distress, depression or anxiety [5, 9]. The mental health service is not yet an integral part of the primary health care system of the country. The training provided to mid-level health workers includes minimal content of mental health and often no practical exposure at all. It has to be noted that majority of the health care services are delivered by these mid-level health workers (health assistants, nurses, auxiliary health workers and auxiliary nurse midwives). Inadequate training to these health workers is a major reason for the gap in the mental health services in the grass root level of Nepal. While there are already promising evidence for the effectiveness of community workers led intervention for mental health services in India [13, 14], similarly elsewhere [15], similar efforts to evaluate the effectiveness of community workers led psychiatric mental health services is non-existent in Nepal. Therefore, community-led psychiatric mental health services should be a research agenda to pursue.

\section{Challenges to universal mental health coverage}

An earlier study using the tool developed by the PRogramme for Improving Mental health carE (PRIME) consortium to systematically 
analyse and describe the current gaps in mental health care in Nepal [10], found several challenges at district, which included overburdened health workers, lack of psychotropic medicines in the PHC, lack of mental health supervision in the existing system, and lack of a coordinating body in the $\mathrm{MoH}$. The same study laid several strategies to overcome these challenges, which includes involvement of MoH in the process, by strengthening drug delivery mechanism for psychotropic medicines, adequate sanctioning of senior level workers in care, and involvement of national training centre in mental health training programs [10].

Matrika Devkota, a leading mental health activist from Koshish, a "self-help" organization says that mental health infrastructure and the human resources available are inadequate to meet the need [16] resulting into most psychiatric wards of hospitals in the country being staffed by general nursing staff without specialized mental health training. Regarding the professional or consumer organization that speak for and advocate for right of mentally ill people, he says 'there is not any' [16]. So, there is need of civil society groups, consumer organization and strong grass root efforts to further drive momentum for mental health services in Nepal.

Stigmatization of the people and families of the person with mental illness is a major problem in Nepal that further complicates the matter [17]. They are regarded as dangerous, aggressive, and having an incurable disease. This belief not only increases the social distance but also increases their vulnerability to abuse, maltreatment and lack of access to social services. Mental illness are viewed from a magical, religious and supernatural lens, often the treatment for the illness is sought traditionally with same principle in use [17]. This is partly due to lower mental health literacy. Therefore, future mental health program in Nepal should focus on mental health literacy, along with scaling up the coverage of services.

\section{Political development in Nepal and risk to mental health problems}

Historically, health sector is under-resourced in Nepal. While, preventive services enjoys only $14 \%$ of total government's expenditure in health [18], preventive services to mental illness is neglected. However, what was needed was a more focus on prevention of mental illness, per se anxiety, depression and psychological distress budged out from the decade of civil war and political turmoil. The future seems even more challenging due to the increment in ageing population, rampant migration and the need to manage the consequences of damages to health sector after recent earthquakes amidst pragmatically non-functioning governance. While the West believes Nepalese society as the last Sangri-la, the last two generations of the country has always suffered violence in many ways. From repeated revolts to bring back democracy from autocratic rana regime around the end of second world war to Jhapa uprising [19], constitutional coup by then King Mahendra in 1960 and during referendum in 1980, political movement for democracy thereafter in 1990, and guerrilla style revolt starting in 1996 by Maoist, suffering to people has increased both physically and mentally during these periods. A total of 16,000 were killed in decade long Maoist revolt, thousands (no exact figures available) were disappeared either from state side or the rebellion resulting into more than two hundred thousand population displaced as internally displaced population. Many of those missing individuals are deemed killed, and their families live with tremendous trauma hoping for justice, peace and euphoria of happiness [20]. Even after the end of war and the fall of autocratic regime leading to federal democratic republic government, the state has taken blind eye to political violence in war, which we believe is a heightened stage of impunity in Nepal, and loss of hope for justice among survivors of violence. However, in the absence of paucity of evidence on the link between these social determinants including violence and mental health, we might just end up speculating. Due to lack of longitudinal observation of social determinants, political violence and mental health, these facts merely rely on speculations and anecdotal evidences [20].

\section{Post armed conflict period and mental health risk}

The repetitive loss and stress due to conflict in Nepalese community is a public health concern which needs urgent and accountable attention. About ten years ago in 2007, before the first constitutional election, many ethnic demonstrations started with demand to have Terai as a separate province and even separate local governance units for each ethnic group, in some extreme cases displacement of minority ethnic groups of Hill origin from southern central Terai. The issue was hoped to resolve after the constituency assembly election and endorsement of new constitution. However, it did not come to a "happy ending". After endorsement of the constitution in September 2015, there was another political agitation from Terai based parties in the country with widespread killings from both state and demonstrator. There is a sense of insecurity, hopelessness, hostility and growing risk of communal violence between (Hill and Terai) ethnic groups. There could be an increment of anxiety and post-traumatic stress disorder as consequences of such crises in the country. Murthy \& Lakshminarayana [21] state the consequences of crises situation could lead to an increase in the burden of mental disorders with women being more affected than men; not limiting to them are children, the elderly and the disabled.

We fear that the burden of mental illness will further escalate if adequate attention is not given now to provide mental health services addressing range of mental health disorders including PTSD. There are several reasons for our concern. Even during the earthquakes, addressing psychological distress never got an adequate attention neither from the government, civil society and the foreign medical teams. Patients were treated in clumsy temporary camps, with virtually no space for mental health counselling. Evidence available has shown that the prevalence of mental health problems among earthquake survivors is high even after months of earthquake with major problems being depression, anxiety, alcohol abuse, suicidal ideation and PTSD [22, 23]. Even after the ten years of peace accord and two years of earthquakes, government response to mental health is not only half hearted but also desultory. The government has failed to improve the coverage and quality of mental health services and account the multifactorial determinants of mental illness in its first "Multi-sectoral NCD Prevention Plan 2014-2020" and mental health policy formed two decades back. Further, significant damage to health infrastruc- 
tures will jeopardize the access to mental health services along with access to other services in post-earthquake setting.

\section{Conclusions}

Nepal has a high burden of mental illness owing to decades of crises that still continue. Despite higher burden, mental illness remains under prioritized and underfunded for prevention, care and treatment. Lack of institutional and financial capacity, poor mechanism for financial risk protection and inadequate human resources compounds the problem furthermore. An increased attention is required to increase awareness on mental health issues via public health measures. The western model of psychiatric service is unlikely to be effective in the local cultural context [24]. With the experience of such long term trans-generational trauma and unique cultural characteristics, mental health service should no longer remain a neglected issue. We argue that the mental health services should be culturally adapted to meet the local needs and focussed on strengthening Nepalese health system.

\section{References}

1. Mullan Z. Rebuilding Nepal. The Lancet Global health. 2015;3(11):e654.

2. The Lancet. Nepal: man-made disaster looms. The Lancet. 2015;386(10010):2228.

3. WHO. Mobile health clinics help tackle post-earthquake mental health problems in Nepal Geneva,2015 [Available from: http://www.who.int/features/2015/mentalhealth-in-nepal/en/.

4. Cerdá M, Paczkowski M, Galea S, Nemethy K, Péan C, Desvarieux M. Psychopathology in the aftermath of the Haiti earthquake: a population-based study of posttraumatic stress disorder and major depression. Depression and anxiety. 2013;30(5):413-24.

5. Kohrt BA, Hruschka DJ, Worthman CM, Kunz RD, Baldwin JL, Upadhaya N, et al. Political violence and mental health in Nepal: prospective study. The British Journal of Psychiatry. 2012;201(4):268-75.

6. Jordans MJ, Kaufman A, Brenman NF, Adhikari RP, Luitel NP, Tol WA, et al. Suicide in South Asia: a scoping review. BMC psychiatry. $2014 ; 14(1): 358$.

7. Sherchan S, Samuel R, Marahatta K, Anwar N, Van Ommeren MH, Ofrin R. Post-disaster mental health and psychosocial support: Experience from the 2015 Nepal earthquake. WHO South-East Asia Journal of Public Health. 2017;6(1):22.

8. MoH. National Mental Health Policy. Kathmandu: Ministry of Health; 1996.

9. WHO. Mental Health System in Nepal. Geneva: WHO; 2006.

10. Luitel NP, Jordans MJD, Adhikari A, Upadhaya N, Hanlon C, Lund C, et al. Mental health care in Nepal: current situation and challenges for development of a district mental health care plan. Conflict and Health. 2015;9:3.

11. Mishra SR, Khanal P, Karki DK, Kallestrup P, Enemark U. National health insurance policy in Nepal: challenges for implementation. Global health action. 2015 Dec $1 ; 8(1): 28763$

12. Institute of Medicine 2017. Detail Notice of Post Graduate Entrance Exam 2073/74 Kathmandu: Examination Control Division; 2017 [Available from: https://drive. google.com/file/d/0Bxlhgj3yFXkuZXU4QVZuRkpYaGM0NFdGTzFuQVp0a09xT2hZ/view.

13. Patel V, Weiss HA, Chowdhary N, Naik S, Pednekar S, Chatterjee S, et al. Effectiveness of an intervention led by lay health counsellors for depressive and anxiety disorders in primary care in Goa, India (MANAS): a cluster randomised controlled trial. Lancet (London, England). 2010;376(9758):2086-95.

14. Patel V, Weiss HA, Chowdhary N, Naik S, Pednekar S, Chatterjee S, et al. Lay health worker led intervention for depressive and anxiety disorders in India: impact on clinical and disability outcomes over 12 months. The British Journal of Psychiatry. 2011;199(6):459-66.

15. Mutamba BB, van Ginneken N, Smith Paintain L, Wandiembe S, Schellenberg D. Roles and effectiveness of lay community health workers in the prevention of mental, neurological and substance use disorders in low and middle income countries: a systematic review. BMC Health Services Research. 2013;13(1):1-11.

16. Devkota M. Mental health in Nepal: The voices of Koshish 2011 [Available from: http://www.apa.org/international/pi/2011/07/nepal.aspx.

17. Lauber C, Rössler W. Stigma towards people with mental illness in developing countries in Asia. International Review of Psychiatry. 2007;19(2):157-78.

18. MoH. Nepal National Health Accounts 2009/10- 2011/12. In: PPICD, editor. Kathmandu: Ministry of Health; 2016.

19. Nepali Times. The original Maoist Kathmandu, Nepal: Nepali Times 2011 [Available from: http://www.nepalitimes.com/blogs/thebrief/2015/10/11/the-original-maoist/.

20. Tol WA, Kohrt BA, Jordans MJ, Thapa SB, Pettigrew J, Upadhaya N, et al. Political violence and mental health: a multi-disciplinary review of the literature on Nepal. Social science \& medicine. 2010;70(1):35-44.

21. Murthy RS, Lakshminarayana R. Mental health consequences of war: a brief review of research findings. World Psychiatry. 2006;5(1):25-30.

22. Kane J, Luitel N, Jordans M, Kohrt B, Weissbecker I, Tol W. Mental health and psychosocial problems in the aftermath of the Nepal earthquakes: findings from a representative cluster sample survey. Epidemiology and psychiatric sciences. 2017:1-10.

23. Jha A, Shakya S, Zang Y, Pathak N, Pradhan PK, Bhatta KR, et al. Identification and treatment of Nepal 2015 earthquake survivors with posttraumatic stress disorder by nonspecialist volunteers: an exploratory cross-sectional study. Indian journal of psychiatry. 2017;59(3):320.

24. Neuner F, Elbert T. The mental health disaster in conflict settings: can scientific research help? BMC public health. 2007;7:275 